\title{
Application of short message service to control blood cholesterol: a field trial
}

\author{
Saeed Sadeghian ${ }^{1}$, Mohsen Shams², Zahra Alipour ${ }^{3}$, Soheil Saadat ${ }^{4,{ }^{*}}$, Reza Hamidian ${ }^{3}$ and Maryam Shahrzad ${ }^{1}$
}

\begin{abstract}
Background: Despite recommendations, many middle-age adults neglect to check their blood cholesterol levels. Short message service (SMS, also known as texting) has been seldom studied for preventive education. We estimated how SMS can be a cost-effective method in encouraging people to check their blood cholesterol levels.

Methods: In a field trial, 3600 cell phone users (age > 30) were randomly assigned to the intervention ( $\mathrm{N}: 1200)$ and the control groups (N: 2400). An SMS was sent to the intervention group for five rounds every two weeks, which targeted the cognitive and affective learning and finally advised the blood cholesterol level to be checked, if not checked during the past twelve months. Two weeks after the last round, both groups were asked for the time/level of their latest blood cholesterol, family history of early cardiac death and having a family member with coronary heart disease (CHD), and to report their attitude about whether annual blood sampling is worth the cost and time to prevent CHD. Moreover, the intervention group was asked if they remembered the SMS content. The cost-effectiveness was evaluated by estimating the "number needed to treat" (NNT) and calculating the cost of sending SMS to that number of people.

Results: In the intervention group, 629 individuals (72.0\%) recalled the SMS content. The factors associated with cholesterol screening during the past two years were older age, diabetes, family history of coronary disease, higher education, female gender and being non-smoker. In both groups, women were significantly more aware of their blood cholesterol level (68.7\% vs. 53.6\%). The relative frequency of respondents who believed it was not worth checking their cholesterol annually was significantly lower in the intervention group $(P<0.001)$. The intervention group was significantly more likely to check its blood cholesterol levels (OR:1.22) after adjustment for age, diabetes, family history of CHD and smoking. The NNT was estimated $\approx 25$ for the general population and $\approx 11$ for those who received SMS and had a family member with CHD.
\end{abstract}

Conclusions: We would postulate that SMS could affect people's adherence to preventive programs. Relatives of patients admitted with a diagnosis of CHD should be prioritized for superior cost-effectiveness and logistical feasibility.

Keywords: Short message service, Blood cholesterol, Coronary disease

\section{Background}

Coronary heart disease (CHD) is among the main causes of morbidity and mortality across the world; Iran is no exception [1, 2]. High cholesterol level is a major cause of disease burden in both the developed and developing countries, which roughly causes 2.6 million deaths $(4.5 \%$

\footnotetext{
* Correspondence: soheil.saadat@gmail.com; soheilsaadat@sina.tums.ac.ir

${ }^{4}$ Sina Trauma and Surgery Research Center, Tehran University of Medical

Sciences, Tehran, Iran

${ }^{5}$ Department of e-Health, Virtual School, Tehran University of Medical

Sciences, Tehran, Iran

Full list of author information is available at the end of the article
}

of total deaths) and 29.7 million disability-adjusted life years (DALYS) [3]. That is why a diagnosis of dyslipidemia is important, especially in individuals at higher risk of CHD, because dyslipidemia is associated with increased risk of cardiovascular events [4,5]. Although the National Cholesterol Education Program Adult Treatment Panel III (NCEP ATP III) recommends starting universal screening for high cholesterol levels at the age of 20 [6], many adults between the ages 20 and 44 years have missed the opportunity to get their blood cholesterol levels checked in their past 5 years [4]. 
Some studies have demonstrated that a well-designed health education program can enhance people's adherence to screening programs by means of raising their awareness and increasing their knowledge of health [7]. The past decade has witnessed the increasing popularity of cell phones in most countries. The vast majority of adult Iranians own cell phones and texting (by using short message service, or SMS) is a very common practice among cell phone users in Iran. Therefore, SMS could be utilized for educational interventions for a large segment of the population at any time or place. Simplicity, low cost, widespread use and instant delivery are the rewarding features of employing this particular method $[8,9]$.

SMS-related improvements in healthcare outcomes have been reported in form of improved outpatient clinic attendance, encouragement for weight loss, compliance with taking medication, growing support for diabetic and asthmatic patients, increased smoking quit rates and increased sunscreen application $[8,10]$. However, most of these studies have focused on clinical care interventions in sick individuals and there has been a paucity of information in the domain of prevention in healthy individuals. As an example of the latter group, a recent study showed that a telemonitoring program via SMS was an effective strategy in the secondary prevention of acute coronary syndrome survivors [11]. Park et al. also reported improved control of blood pressure, body weight, waist circumference and HDL-C levels in patients with concomitant obesity and hypertension after eight weeks of SMS intervention [12].

In the present study, we studied the cost-effectiveness of SMS as a tool to encourage people to check their blood cholesterol levels. To the best of the authors' knowledge, this is the first published study that focuses on the cost-effectiveness of SMS in encouraging people to control a CHD risk factor.

\section{Methods \\ Study design}

An advertising company specializing in text commercials and surveys was hired to randomly select from its data pool three thousand and six hundred cell phone users who were older than thirty years old and residents of the Tehran Metropolitan Area in the year 2008. The company sent SMS to the participants and transferred their anonymized information to the authors. The study was a field trial, where participants were randomly assigned to either the intervention or the control group. The allocation ratio was 1:2 respectively (Fig. 1). An SMS package was sent to the intervention group for five rounds, every two weeks. At each round, the intervention group was sent a daily message on three consecutive days, beginning with the first day of the workweek. The message sent on the first day targeted the cognitive learning of the recipient, explaining that high blood cholesterol was a major risk factor of CHD. The second day's message aimed toward the affective learning suggesting that it was worth checking blood cholesterol annually for the prevention of CHD development. The third day's message was a psychomotor-based approach that directly advised the recipient to get blood cholesterol level checked as soon as possible if (s)he was thirty years of age or older, especially if (s)he had not checked it during the prior twelve months. All the messages were subscribed by Tehran Heart Center as the sender and the length of each SMS was restricted to a single message.

Both groups were reached via a phone call two weeks after the dispatch of the last round of messages. Overall,

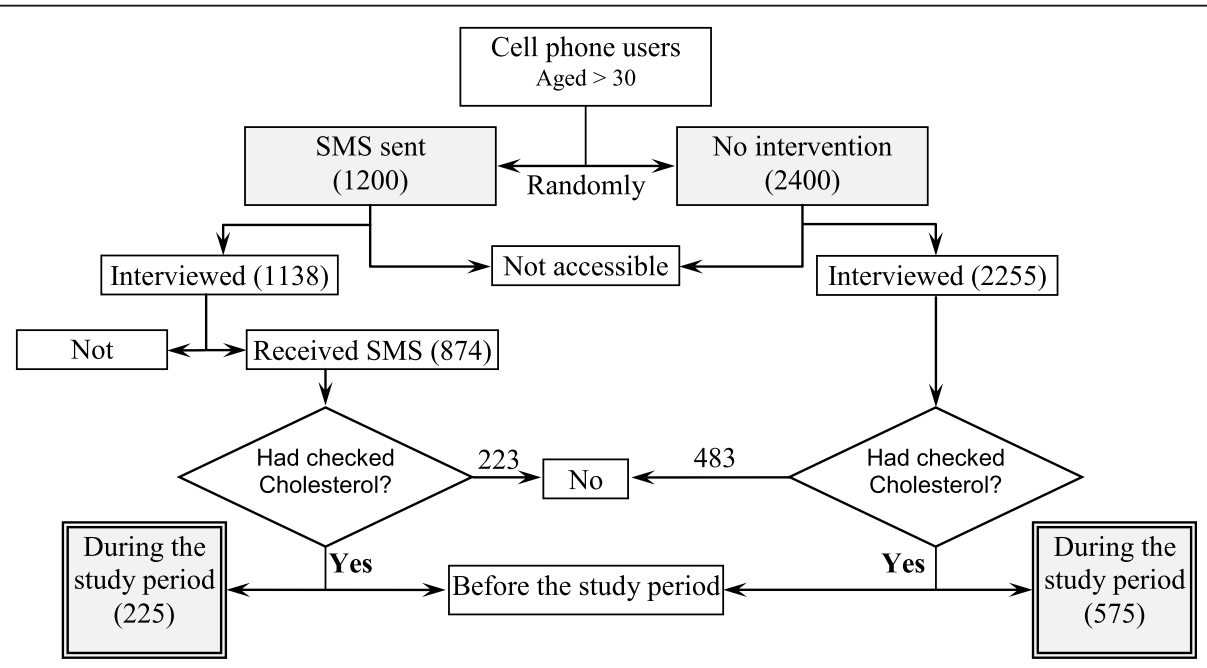

Fig. 1 Study design for application of short message service (SMS) to control blood cholesterol: a field trial 
1138 (94.8\%) and 2255 (94.0\%) participants in the intervention and the control group responded, respectively. During the interview period, the participants remained anonymous. Participants were informed at the beginning of the interview that a) this was a research study gathering no identifying information, b) the participants have the right not to answer any question at their discretion, and c) the participants are free to end their contribution to the study at any time for any reason.

The respondents were asked when they had last checked their blood cholesterol levels, what its value was, whether or not they had a family history of early cardiac death and if they had a family member with CHD. Additionally, both groups' demographics including age, sex, education level, occupation, history of smoking and status of diabetes mellitus were collected. The intervention group was asked if they had received any SMS from Tehran Heart Center and whether they can remember its content. The respondents were asked to report their attitude toward this statement: "Is annual blood sampling worth the cost and time to prevent CHD?"

\section{Statistical analysis}

The data were analyzed using SPSS 13.0 software (IBM Corp., USA). The continuous data are shown as mean ( \pm standard deviation $[\mathrm{SD}]$ ). The chi-square test was used to compare the categorical data between the groups for univariable analysis, and a logistic regression model was employed for multi-variable analysis.

In the logistic regression model, "checking blood cholesterol during the study period" was considered as the dependent variable. "Receiving the educational text" was the independent variable of interest. The effects of age, being diabetic, a family history of $\mathrm{CHD}$, higher education, and smoking on association of the dependent variable and the main independent variable were controlled by including them in the model.

The cost-effectiveness of the SMS intervention was evaluated by estimating the "number needed to treat" (NNT) and calculating the cost of sending SMS to that specific number of people. The NNT is the average number of subjects who need treatment to prevent one additional adverse outcome (for example, the number of patients that need treatment for its benefit compared with control subjects in a clinical trial). The NNT represents the inverse of absolute risk reduction. To estimate the NNT based on adjusted Odds Ratio (OR), the following formula was applied:

$\mathrm{NNT}=\mid(1-(\mathrm{PEER} \times(1-\mathrm{OR}))) /((1-\mathrm{PEER}) \times(\mathrm{PEER}) \times(1-\mathrm{O}$ $\mathrm{R}))$; w where PEER is the prevalence of checking blood cholesterol levels during the study period in the unexposed (control) group.

\section{Results}

The intervention and the control groups consisted of 1200 and 2400 cell phone users, respectively. The authors were unable to reach 205 participants (62 from the intervention and 145 from the control group) (Fig. 1). In the intervention group, 874 individuals $(76.8 \%)$ confirmed that they had received the messages, and 629 persons $(72.0 \%)$ correctly recalled the message content. The basic characteristics of the respondents are depicted in Table 1.

Of all the study participants, 1322 individuals (36.7\%) had not checked their blood cholesterol levels during the past two years. The variables associated with an absence of blood cholesterol screening during the past two years are presented in Table 2.

The proportion of people who had never checked their blood cholesterol levels was twice as much in men $(27.0 \%)$ than in women $(13.3 \%)$, which was statistically significant $(P<0.001)$. Table 3 demonstrates blood cholesterol levels in respondents who recalled it during the interview.

Regardless of the study group, women were significantly more aware of their blood cholesterol levels than men were $(68.7 \%$ vs. $53.6 \%, P<0.001)$.

\section{Attitude}

The relative frequency of the respondents who believed it was not worth checking their blood cholesterol levels annually in terms of the cost and time needed was $6.46 \%$

Table 1 Characteristics of study groups in the application of short message service (SMS) to control blood cholesterol: a field trial

\begin{tabular}{lll}
\hline Characteristics & $\begin{array}{l}\text { Control (No SMS) } \\
\text { Number (\%) }\end{array}$ & $\begin{array}{l}\text { Intervention } \\
\text { (received SMS) } \\
\text { Number (\%) }\end{array}$ \\
\hline Male & $1380(61.2)$ & $680(59.8)$ \\
Smoker & $384(17.0)$ & $240(21.1)$ \\
Diabetic & $87(3.9)$ & $33(3.0)$ \\
Family History & & \\
CHD & & $311(27.3)$ \\
Early cardiac death & $165(7.3)$ & $111(9.8)$ \\
Education & & $5(0.4)$ \\
Illiterate & $17(0.8)$ & $125(11.0)$ \\
Up to middle school & $245(10.9)$ & $311(27.3)$ \\
Up to high school & $450(20.0)$ & $56(4.9)$ \\
Diploma & $114(5.1)$ & $278(24.4)$ \\
College & $391(17.3)$ & $106(9.3)$ \\
Bachelor or higher & $192(8.5)$ & $257(22.6)$ \\
Declined to respond & $846(37.5)$ & $41.99( \pm 9.17)$ \\
Age (year \pm SD) & $40.15( \pm 12.42)$ &
\end{tabular}

${ }^{a} \mathrm{CHD}$, coronary heart disease; ${ }^{\mathrm{b}} \mathrm{SD}$, standard deviation 
Table 2 Variables associated with absent blood cholesterol checks during two years prior to the study

\begin{tabular}{|c|c|c|c|}
\hline Variables & Coefficient & $P^{c}$ & $\mathrm{OR}^{\mathrm{d}}$ \\
\hline Receiving SMS ${ }^{a}$ & -0.170 & 0.063 & 0.844 \\
\hline Older age & -0.052 & $<0.001$ & 0.949 \\
\hline Diabetes mellitus & -0.686 & 0.001 & 0.504 \\
\hline Family history of $\mathrm{CHD}^{\mathrm{b}}$ & -0.240 & 0.010 & 0.786 \\
\hline Higher education & -0.202 & $<0.001$ & 0.817 \\
\hline Sex (female vs. male) & -0.272 & 0.014 & 0.762 \\
\hline Smoking & 0.496 & $<0.001$ & 1.642 \\
\hline Constant & 4.216 & & \\
\hline
\end{tabular}

${ }^{\mathrm{a}} \mathrm{SMS}$, short message service; ${ }^{\mathrm{b}} \mathrm{CHD}$, coronary heart disease; ${ }^{\mathrm{C}} \mathrm{P}, \mathrm{P}$ value; ${ }^{\mathrm{d}} \mathrm{OR}$, odds ratio

in the control group and $3.25 \%$ in the intervention group $(P<0.001)$.

\section{Practice}

Eight hundred participants had checked their blood cholesterol levels during the intervention period (Fig. 1). In the multivariable analysis, the intervention group participants were more likely to check their blood cholesterol levels in comparison to the control participants (OR: 1.22) after adjustment for age, diabetes mellitus status, family history of CHD and history of smoking; the difference constituted statistical significance (Table 4).

\section{Cost-effectiveness}

The cost of using SMS was about 0.01 USD (United States Dollar) per message at the time of the study. Fifteen text messages were sent to every person in the intervention group; however, only $76.8 \%$ acknowledged the receipt of the messages during the interview period. Accordingly, the cost of a successful SMS delivery to a single person was 0.195 USD.

Table 3 The blood cholesterol levels (mean [ \pm standard deviation]) in study participants who checked and recalled their blood cholesterol levels

\begin{tabular}{lll}
\hline Variable & $\begin{array}{l}\text { Blood cholesterol level }(\mathrm{mg} / \mathrm{dl}) \\
\text { Mean }( \pm \text { SD) }\end{array}$ & $\mathrm{N}$ \\
\hline Sex & & 163 \\
Male & $214.4( \pm 74.7)$ & 61 \\
Female & $210.8( \pm 47.0)$ & \\
DM $^{a}$ & & 13 \\
Yes & $200.1( \pm 32.6)$ & 211 \\
No & $214.3( \pm 69.6)$ & \\
Smoking & & 47 \\
Yes & $226.3( \pm 79.7)$ & 177 \\
No & $209.3( \pm 64.1)$ & \\
\hline
\end{tabular}

${ }^{\mathrm{a} D M}$, diabetes mellitus
Table 4 Variables associated with checking blood cholesterol levels during the intervention period

\begin{tabular}{lcll}
\hline Variables & Coefficient & $P^{c}$ & $\mathrm{OR}^{\mathrm{d}}$ \\
\hline Receiving SMS & 0.200 & 0.033 & 1.22 \\
Older age & 0.043 & $<0.001$ & 1.04 \\
Diabetes mellitus & 0.754 & $<0.001$ & 2.13 \\
Family history of CHD & 0.248 & 0.009 & 1.28 \\
Higher education & 0.130 & $<0.001$ & 1.14 \\
Smoking & -0.418 & $<0.001$ & 0.66 \\
Constant & -3.987 & $<0.001$ &
\end{tabular}

${ }^{\mathrm{a}} \mathrm{SMS}$, short message service; ${ }^{\mathrm{b}} \mathrm{CHD}$, coronary heart disease; ${ }^{\mathrm{C}} \mathrm{P}, \mathrm{P}$ value; ${ }^{\mathrm{d}} \mathrm{OR}$, odds ratio

In the control group, 25.5\% had checked their blood cholesterol levels. Therefore, the NNT can be calculated as $(1-(0.255 \times(1-1.22))) /((1-0.255) \times(0.255) \times(1-1.22))$ $\approx 25$ for the general population. The Odds Ratio (OR) for those who had received messages and had a family member with CHD was estimated to be $\mathrm{e}^{(0.200+0.248)}=1.57$, with the NNT being about 11 for this specific group.

\section{Discussion}

Screening young adults for serum lipid disorders is recommended by numerous specialties, particularly young adults with CHD, CHD equivalents or individuals with one or more cardiac risk factors [13, 14]. Nevertheless, convincing healthy people to take action and check their blood lipid levels appears to be almost a farfetched achievement [10]. As found in our study, 39\% of the respondents had not checked their blood cholesterol levels during the two-year period leading up to our study.

We used cellular texting (SMS) as a tool for the reminder strategy in order to increase knowledge and attitude toward the important role that cholesterol plays in developing $\mathrm{CHD}$, as well as increasing healthy people's adherence to a preventive behavior toward CHD. We noted that this strategy inspired one out of twenty-five people in the general population to actually check his/ her blood cholesterol level. We also found that the NNT for this intervention was less for people with a positive family history of CHD; therefore, the effectiveness of this strategy could be enhanced by focusing on the relatives of CHD patients.

During the intervention period, the attitude of the intervention group toward checking their cholesterol levels, regardless of the required time and money, was improved and this result was in accordance with the improvement in the preventive practice of testing the blood cholesterol level. Improvement in healthcare outcomes has been reported in previous studies examining the use of SMS [8, 10]; however, when Cocosila et al. evaluated the usefulness of SMS, they found non-significant 
improvement in healthy people's adherence to taking vitamin C [9].

In the context of health economics, the cost of motivating a person in the general population to actually check his/her blood cholesterol level was $4.9\left(25_{\mathrm{NNT}} \times 0.195_{\text {cost }}\right.$ of successful SMS delivery) USD. The cost-effectiveness of this strategy could be augmented by restricting the target population to the relatives of high-risk $\mathrm{CHD}$ patients. With this restriction in mind, it would cost 2.1 USD per person to inspire a healthy relative of a high-risk CHD patient to do a screening for blood cholesterol level. A few studies in the existing literature have evaluated the costeffectiveness of texting. Chen et al. [15] showed that reminding each patient of an appointment via SMS was significantly cheaper (0.31 Yuan per SMS) than telephone (0.48 Yuan per call). Koshy et al. [16] also used SMS reminders for ophthalmology outpatient appointments and concluded it was more cost-effective and less demanding than traditional methods.

The cost-effectiveness of the texting strategy also depends on the optimum number of messages, which demands further studies.

In the present study, female respondents were more aware of their cholesterol level and also checked their blood cholesterol levels twice as much as male participants. Considering the role of the male gender as an independent CHD risk factor [17], specific interventions are required, in order to propel men to enhance their health awareness. Furthermore, this result regarding gender as a factor can be interpreted as a sign of women having more sensitivity and attention to their health concerns [18].

In this study we randomly texted general population. Since higher blood cholesterol levels are expected in certain populations such as males, diabetics and smokers [19-21], stratification of the target group according to sex, existence of diabetes mellitus and smoking may yield better results. For this reason, these specific groups must be prioritized for screening programs.

During the study period, we addressed two important reasons for non-adherence within the participants: forgetfulness that was addressed by means of sending reminders every two weeks, and lack of knowledge, which was addressed by sending texts, which pointed the importance as well as one serious side effect of having high blood cholesterol levels [8].

In the light of our study results, we would postulate that SMS could affect people's adherence to preventive programs for several reasons. As stated before, cell phones are widely used across Iran, and texting by using SMS is a common practice. Simplicity, efficiency, confidentiality [22], affordability and feasibility are also among the reasons why SMS use should be considered for preventive programs $[8,10]$.
In spite of these unique features of SMS, we should bear in mind that certain groups are less likely to access cell phones or be adequately educated to read texts. Those groups including, though not limited to, the unemployed, the destitute, the illiterate and the elderly need further education or assistance regarding the use of SMS. Another important limitation of this strategy was highlighted by our study; in the sense that the correct recollection of the message content was only $55.3 \%$ of the intervention group's participants.

\section{Conclusions}

In this study, we were able to document the effectiveness of utilizing SMS as a preventive strategy for CHD. However, further research is needed to determine the optimal number of SMS messages to be sent, the optimal interval between the messages, and the most efficacious content and wording of the messages when accounting for different populations (for instance, people with dissimilar occupations and educational background).

\section{Abbreviations}

CHD: Coronary heart disease; DALYS: Disability-adjusted life years; DM: Diabetes mellitus; NNT: Number needed to treat; OR: Odds ratio; SD: Standard deviation; SMS: Short message service; USD: United States Dollar

\section{Acknowledgements}

Not applicable.

\section{Funding}

This research study was funded by Tehran University of Medical Sciences, Tehran Heart Center; however, Tehran University of Medical Sciences was not involved in the analysis and interpretation of data, the writing of the report, and in the decision to submit the article for publication. This research did not receive any specific grant from funding agencies in the public, commercial, or not-for-profit sectors.

\section{Availability of data and materials}

The datasets generated and/or analyzed during the current study are not publicly available, due to privacy restrictions on the participants' part; however, they can be provided by the corresponding author provided a reasonable request.

\section{Authors' contributions}

SS designed the study, performed acquisition and interpretation of the data, drafted and revised the manuscript, and gave final approval for submission. MS designed the study, performed interpretation of the data, drafted the manuscript, and gave final approval for submission. ZA designed the study, performed acquisition and interpretation of the data, drafted and revised the manuscript, and gave final approval for submission. SS (2) designed and managed the study, performed acquisition, analysis and interpretation of the data, drafted and revised the manuscript, and gave final approval for submission. RH designed the study, performed acquisition of the data, revised the manuscript, and gave final approval for submission. MS (2) performed acquisition and interpretation of the data, drafted the manuscript, and gave final approval for submission. All authors read and approved the final manuscript.

\section{Competing interests}

The authors declare that they have no competing interests.

Consent for publication

Not applicable. 


\section{Ethics approval and consent to participate}

The Ethics Committee of Tehran University of Medical Sciences granted ethics approval to the current study and waived the need for obtaining signed informed consent from participants for the following three reasons: Firstly, this field trial was executed via telephone texting and follow-up interviews, the participants were physically unavailable, due to being selected from vast metropolitan areas. Secondly, all participants were enrolled anonymously by the means of selecting random phone numbers via a computer software owned by a third-party mobile operator. Since no questions regarding the identity of the participants were asked during the follow-up interview, their identity remained anonymous throughout the study. Lastly, since all the participants were physically unavailable, they expressed their verbal consent for the authors to use the information obtained during the study for publication on the condition that they would remain anonymous.

\section{Publisher's Note}

Springer Nature remains neutral with regard to jurisdictional claims in published maps and institutional affiliations.

\begin{abstract}
Author details
${ }^{1}$ Tehran Heart Center, Tehran University of Medical Sciences, Tehran, Iran.

${ }^{2}$ Social Determinants of Health Research Center, Yasuj University of Medical Sciences, Yasuj, Iran. ${ }^{3}$ Sina Research Development Center, Tehran University of Medical Sciences, Tehran, Iran. ${ }^{4}$ Sina Trauma and Surgery Research Center, Tehran University of Medical Sciences, Tehran, Iran. ${ }^{5}$ Department of e-Health, Virtual School, Tehran University of Medical Sciences, Tehran, Iran.
\end{abstract}

Received: 23 October 2016 Accepted: 16 March 2017

Published online: 28 March 2017

\section{References}

1. Fatemi SS, Hasanzadeh M, Arghami A, Sargolzaee MR. Lipid profile comparison between opium addicts and Non-addicts. J Teh Uinv Heart Ctr. 2008;3:169-72

2. Neubeck L, Redfern J, Fernandez R, Briffa T, Bauman A, Freedman SB. Telehealth interventions for the secondary prevention of coronary heart disease: a systematic review. Eur J Cardiovasc Prev Rehabil. 2009;16:281-9. doi:10.1097/HJR.0b013e32832a4e7a.

3. Global Health Observatory $(\mathrm{GHO})$ data. Raised cholesterol. http://www.who. int/gho/ncd/risk_factors/cholesterol_text/en/. Accessed 3 Oct 2016.

4. Kulinka EV, Yoon PW, Keenan NL. Prevalence of coronary heart disease risk factors and screening for high cholesterol levels among young adults, United States, 1999-2006. Ann Fam Med. 2010;8:327-33. doi:10.1370/afm. 1137.

5. Tóth PP, Potter D, Ming EE. Prevalence of lipid abnormalities in the United States: the National Health and Nutrition Examination Survey 2003-2006. J Clin Lipidol. 2012;6:25-30. doi:10.1016/j.jacl.2012.05.002.

6. Expert Panel on Detection, Evaluation, And Treatment of the High Blood Cholesterol in Adults. Executive Summary of The Third Report of The National Cholesterol Education Program (NCEP) Expert Panel on Detection, Evaluation, And Treatment of the High Blood Cholesterol in Adults (Adult Treatment Panel III). JAMA 2001;285:2486-97. doi:10.1001/jama.285.19.2486

7. Al Sairafi M, Mohamed FA. Knowledge, attitudes, and practice related to cervical cancer screening among Kuwaiti women. Med Princ Pract. 2009:18:35-42. doi:10.1159/000163044.

8. Armstrong AW, Watson AJ, Makredes M, Frangos JE, Kimball AB, Kvedar JC. Text-message reminders to improve sunscreen use: a randomized, controlled trial using electronic monitoring. Arch Dermatol. 2009;145:1230-6. doi:10.1001/archdermatol.2009.269.

9. Cocosila M, Archer N, Haynes RB, Yuan RB. Can wireless text messaging improve adherence to preventive activities? Results of a randomised controlled trial. Int J Med Inform. 2009;78:230-8. doi:10.1016/j.ijmedinf. 2008.07.011.

10. Krishna S, Boren SA, Balas EA. Healthcare via cell phones: a systematic review. Telemed J E Health. 2009;15:231-40. doi:10.1089/tmj.2008.0099.

11. Blasco A, Carmona M, Fernández-Lozano I, Salvador CH, Pascual M, Sagredo PG, Somolinos R, Muñoz A, García-López F, Escudier JM, Mingo S, Toquero J, Moñivas V, González MA, Fragua JA, López-Rodríguez F, Monteagudo JL, Alonso-Pulpón L. Evaluation of a telemedicine service for the secondary prevention of coronary artery disease. J Cardiopulm Rehabil Prev. 2012;32: 25-31. doi:10.1097/HCR.0b013e3182343aa7.

12. Park MJ, Kim HS, Kim KS. Cellular phone and Internet-based individual intervention on blood pressure and obesity in obese patients with hypertension. Int J Med Inform. 2009;78:704-10. doi:10.1016/j.ijmedinf. 2009.06.004.

13. U.S. Preventive Services Task Force. (USPSTF). Screening for Lipid Disorders in Adults, Summary of Recommendations. June 2008. http://www. uspreventiveservicestaskforce.org/Page/Document/UpdateSummaryFinal/lipid disorders-in-adults-cholesterol-dyslipidemia-screening. Accessed 03 Oct 2016.

14. Stone NJ, Robinson JG, Lichtenstein AH, Bairey Merz CN, Blum CB, Eckel RH, Goldberg AC, Gordon D, Levy D, Lloyd-Jones DM, McBride P, Schwartz JS, Shero ST, Smith Jr SC, Watson K, Wilson PW. American College of Cardiology/American Heart Association Task Force on Practice Guidelines. 2013 ACC/AHA guideline on the treatment of blood cholesterol to reduce atherosclerotic cardiovascular risk inadults: a report of the American College of Cardiology/American Heart Association Task Force on Practice Guidelines. J Am Coll Cardiol. 2014;63(25 Pt B):2889-934. doi:10.1016/j.jacc.2013.11.002.

15. Chen ZW, Fang LZ, Chen LY, Dai HL. Comparison of an SMS text messaging and phone reminder to improve attendance at a health promotion center: a randomized controlled trial. J Zhejiang Univ Sci B. 2008;9:34-8. doi:10. 1631/jzus.B071464.

16. Koshy E, Car J, Majeed A. Effectiveness of mobile-phone short message service (SMS) reminders for ophthalmology outpatient appointments: observational study. BMC Ophthalmol. 2008;31:8:9. doi: 10.1186/1471-2415-8-9.

17. Vakili $H$, Kowsari $R$, Namazi MH, Motamedi MR, Safi M, Saadat $H$, Sadeghi $R$, Tavakoli S. Could mean platelet volume predicts impaired reperfusion and in-hospital major adverse cardiovascular event in patients with primary percutaneous coronary intervention after ST-elevation myocardial infarction? J Teh Univ Heart Ctr. 2009;4:17-23.

18. Scuteri A, Najjar SS, Orru' M, Albai G, Strait J, Tarasov KV, Piras MG, Cao A, Schlessinger D, Uda M, Lakatta EG. Age and gender specific awareness, treatment, and control of cardiovascular risk factors and subclinical vascular lesions in a founder population: The SardiNIA Study. Nutr Metab Cardiovasc Dis. 2009:19:532-41. doi:10.1016/j.numecd.2008.11.004.

19. Chelland Campbell S, Moffatt RJ, Stamford BA. Smoking and smoking cessation-the relationship between cardiovascular disease and lipoprotein metabolism: a review. Atherosclerosis. 2008;201:225-35. doi:10.1016/j. atherosclerosis.2008.04.046

20. Chiu YW, Huang CT, Chuang HY, Chang YT, Wu MT, Liu HW. Sex differences in metabolic morbidities: influenced by diet or exercise habit? Kaohsiung J Med Sci. 2009;25:647-55. doi:10.1016/S1607-551X(09)70570-4.

21. Mooradian AD. Dyslipidemia in type 2 diabetes mellitus. Nat Clin Pract Endocrinol Metab. 2009:5:150-9. doi:10.1038/ncpendmet1066.

22. Lim MS, Hocking JS, Hellard ME, Aitken CK. SMS STI: a review of the uses of mobile phone text messaging in sexual health. Int J STD AIDS. 2008;19:28790. doi:10.1258/ijsa.2007.007264.

\section{Submit your next manuscript to BioMed Central and we will help you at every step:}

- We accept pre-submission inquiries

- Our selector tool helps you to find the most relevant journal

- We provide round the clock customer support

- Convenient online submission

- Thorough peer review

- Inclusion in PubMed and all major indexing services

- Maximum visibility for your research

Submit your manuscript at www.biomedcentral.com/submit
Biomed Central 